\title{
René Bloch zum fünfundsiebzigsten Geburtstag
}

René Bloch feierte am Valentinstag seinen fünfundsiebzigsten Geburtstag. Dr. Bloch schaut auf einen Lebensweg zurück voller Hindernisse, die er nie zu umgehen, sondern zu bewältigen versuchte. Schon zu seiner Studentenzeit als Präsident der Klinikerschaft zeichnete er sich durch seinen Mut und sein unabhängiges Denken aus. Bereits einige Jahre vor den Studentenaufständen von 1968 erkannte Bloch, dass ein Generationenkonflikt in der Gesellschaft und auch der Ärzteschaft angegangen werden müsste. So trat er für eine Verbesserung der sozialen Verhältnisse der Medizinstudenten ein. Daneben setzte er sich für eine Anhebung des ethischen Bewusstseins im Rahmen ärztlichen Handelns ein. Sein Eintreten für die Belassung der Universitätskliniken im Zentrum der Stadt Basel, anstelle ihrer Verlagerung an die äusserste Peripherie brachten ihm Feindschaften ein, nicht zuletzt in Dozentenkreisen.

Er doktorierte 1965 zum Thema der Süchte, womit er sich in einen starken Gegensatz zu damals geltenden Auffassungen stellte. Auszüge seiner Dissertation wurden im «Nervenarzt» und in der Zeitschrift für Psychosomatik veröffentlicht.

Seine erste Assistentenzeit verbrachte er in der Waldau in Bern, in einer Umgebung, die seine Idee zu einem neuen Testverfahren begünstigte. Während der Entwicklung des revolutionären Tests musste Bloch zahlreiche Widerstände brechen. Der Zeichentest «MDZT» ist ein quantifizierbares und ebenso gut tiefenpsychologisch analysierbares Verfahren. Das Verfahren hat seinen Anwendungskreis vor allem in der Tschechoslowakei und Ungarn gefunden, während in den westlichen Industrienationen die projektiven Verfahren in den Hintergrund verdrängt wurden, ohne dass die Arbeiten von Bloch die verdiente Würdigung erhalten hätten.
Besonders während seiner Praxisjahre in Basel befasste sich Bloch mit dem Problem der Depressionen, indem er behauptete, dass diese Diagnose zu oft gestellt würde und zu einem Medikamentenmissbrauch geführt hätte. Die Entwicklung hat Bloch insofern recht gegeben, als man heute zum Beispiel nicht mehr von Erschöpfungsdepression, sondern von Burn-out-Syndrom spricht. Seine ganzheitliche Schau der Psychiatrie stellte Bloch 1989 unter Beweis durch die Veröffentlichung des Buches «Droht uns die totale Psychiatrie?».

Ein Angebot zur Habilitation in Mannheim im Jahr 1973 hat Bloch ausgeschlagen. Er zog es vor, in seine Heimatstadt Basel zurückzukehren, der er sich innig verbunden fühlte, auch infolge der zahlreichen Museen und insbesondere des Antiken-Museums, in dem er einen Teil seiner eigenen Sammlung untergebracht hatte. Seit 1987 lebt Bloch in Frankreich.

Marc Girard, Marseille

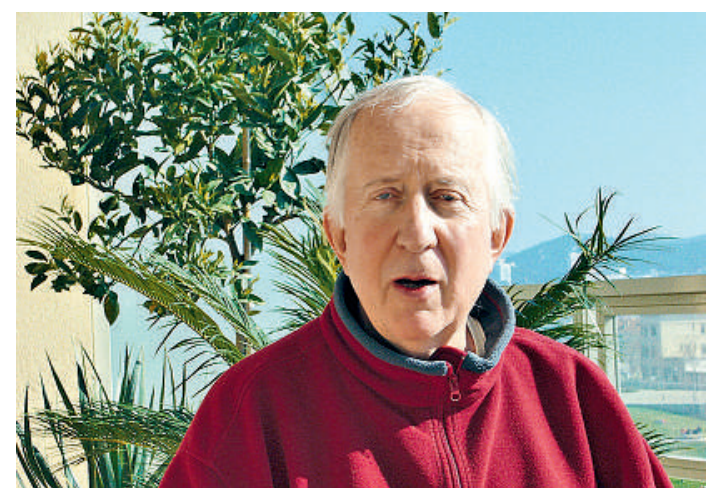

René Bloch lebt in Frankreich, doch seiner Heimatstadt Basel fühlt er sich stark verbunden. 